\title{
Research on the Progress of Systematic Taxonomy in the Genus Asparagus of China
}

Sheng Wentao ${ }^{1}$, Zhang Tonglin ${ }^{1}$, Kuang Quan ${ }^{1}$, Wang Zhangfeng ${ }^{1}$, Luo Shaochun ${ }^{2} \square$

1 Department of Biotechnology, Nanchang Normal University, Nanchang, 330032, China

2 Institute of Vegetables and Flowers, Jiangxi, Academy of Agricultural Sciences, Nanchang, 330200, China

$\square$ Corresponding author email: 1sc200406@sina.com

Molecular Plant Breeding, 2021, Vol.12, No.26 doi: 10.5376/mpb.2021.12.0026

Received: 15 Sep., 2021

Accepted: 25 Sep., 2021

Published: 10 Oct., 2021

Copyright (c) 2021 Sheng et al., This article was first published in Molecular Plant Breeding in Chinese, and here was authorized to translate and publish the paper in English under the terms of Creative Commons Attribution License, which permits unrestricted use, distribution, and reproduction in any medium, provided the original work is properly cited

Preferred citation for this article:

Sheng W.T., Zhang T.L., Kuang Q., Wang Z.F., and Luo S.C., 2021, Research on the progress of systematic taxonomy in the genus Asparagus of China, Molecular Plant Breeding, 12(26): 1-9 (doi: $\underline{10.5376 / \mathrm{mpb} .2021 .12 .0026}$ )

\begin{abstract}
Garden asparagus (Asparagus officinalis L.) is a kind of nutritious and healthy vegetable with important economic value in the world. China has become the largest production country of garden asparagus in the world. But the seeds mainly depend on import, so we need to innovate breeding system and improve the international competitiveness of domestic asparagus varieties. Genetic analysis demonstrated that the genetic variation of garden asparagus was low and its heterosis was weak among cultivars. Inter-specific hybridization is an important means to utilize heterosis, but the relationship between the classical taxonomy and molecular phylogeny of the genus Asparagus is disordered, which limits the development of interspecific hybridization breeding. In this genus, thirty-one species have been found in China, which is an effective genetic resource for the utilization of heterosis among Asparagus species. In order to provide reference for the next step to clarify the phylogenetic relationship of this genus and to carry out the interspecific hybrid breeding of garden asparagus in the near future, the research progress of its classical and molecular phylogeny of this genus is reviewed in this study.
\end{abstract}

Keywords Asparagus officinalis L.; Asparagus; Phylogeny; Inter-species hybridization

Garden asparagus (Asparagus officinalis L.) of the genus Asparagus, is a kind of vegetable with important economic value in the world. It has been introduced into China since the last century. At present, its cultivation in China has developed rapidly, and the cultivation area has reached $1 \times 10^{5} \mathrm{hm}^{2}$, accounting for about $50 \%$ of the world's asparagus yield. Garden asparagus has become the single vegetable variety with the largest export earnings, and the annual output value has exceeded CNY 10 billion (Chen, 2019, China Rural Science Technology, 284: 66-69). With the continuous expansion of asparagus planting scale, China has gradually occupied a dominant position in the world asparagus industry system and put forward higher requirements for the yield and quality of asparagus varieties. As a kind of exotic in China, garden asparagus variety resources and wild relatives are scarcer, which limits the improvement of asparagus breeding level. Germplasm resources are the genetic material basis of garden asparagus hybrid breeding. Garden asparagus, originated in the Mediterranean coastal area, was firstly domesticated and cultivated by the Dutch in the $16^{\text {th }}$ century, with long growth cycle (generally $10 \sim 15$ years ), slow variety renewal and poor germplasm resources (Moreno et al., 2008a). Mercati et al. (2015) confirmed that the genetic background of asparagus varieties was quite narrow by SNP molecular marker technology, and further confirmed that the utilization of heterosis based on intraspecific genetic variation for a long time was difficult to obtain substantive breakthroughs in the cultivation of asparagus varieties (Personal breeding experience). However, there are about 300 species of the genus Asparagus in the world. Except for the Americas, it is distributed in temperate to tropical regions all over the world (Tang and Liang, 1983). The wild germplasm of the genus Asparagus exists in a rich and diverse wild environment. In the process of long-term evolutionary adaptation and species differentiation, it produces a wide variety of secondary metabolites and accumulates strong resistance to biotic and abiotic stresses. Many of these secondary metabolites are important nutrients or have good medicinal value (Norup et al., 2015). For example, A. racemosus, is an important source of medicinally phytoestrogenic species (Boonsom et al., 2012). And A. maritimus not only tolerates salt and alkali but it is also 
resistant to the invasion of important disease pathogens such as rust disease and root rot (Kubota et al., 2012). The excellent traits or gene resources contained in these related wild germplasm resources are the candidate resources that are dreamed of in asparagus genetic improvement. Therefore, it is the basic work for the genetic improvement of germplasm to clarify the phylogenetic relationship of the genus Chinese native and introduced Asparagus plants, and to carry out the interspecific hybrid breeding of garden asparagus.

\section{Overview of the Genus Asparagus and Its Systematic Taxonomy}

\subsection{Overview of the genus Asparagus}

The genus Asparagus was first established by Linné in 1753, and its systematic taxonomy was mostly based on the scientific name published by Antoine Laurent De Jussieu in 1789. The Flora of the Soviet Union (vol.4, 1935) is the most comprehensive and systematic description of the genus Asparagus in temperate regions, which divides 24 species of Asparagus plants into one Subgen. Asparagus. The Flora of China (vol.15, 1978) is an important work to study the genus Asparagus in China. It divides 26 species of Asparagus in China into one subgenus. And this subgenus was divided into two groups: Sect. Archiasparagus Iljin and Sect. Asparagus. Plants in Asparagus belong to Asparagales of Monocotyledoneae, originally belonging to Liliaceae, the latest classification is Asparagaceae. The new division of the family Asparagaceae includes the genus Asparagus in the Old World (Asia, Africa, and Europe continent) and the subgenus Hemiphylacus in Mexico of New World (The Angiosperm Phylogeny Group, 2016). And the genus Asparagus distributed in the Old World can be divided into three subgenera: subgenus Asparagus, Myrsiphyllum, and Protas-paragus. Subgenus Asparagus is plant with unisexual flower and dioecious, mainly distributed in Eurasia and Africa. The subgenus Myrsiphyllum and Protas-paragus are plants with bisexual flowers, and the subgenus Myrsiphyllum is distributed in Africa, while the subgenus Protas-paragus is distributed in Eurasia, Africa, and Australia. Both subgenus Myrsiphyllum and Protas-paragus have combined perianth segments, which are perennial roots, and the aboveground parts are annual herbs. The ovary of the subgenus Myrsiphyllum contains multiple globular ovules, perennial roots, and the aboveground parts are perennial shrubs. So, the genus Asparagus is mainly perennial herbs or semi-shrubs with erect or climbing stems. It often has thick rhizomes, fleshy roots or spindle-shaped tubers, and its taxonomic relationship is constantly changing.

At present, 31 species of this genus have been found in China, including 29 species of wild plants (Garden asparagus is wildly distributed in Tacheng area of Xinjiang) and 3 species of cultivated plants (Asparagus densiflorus, Asparagus setaceus and Asparagus officinalis) (Chen and Tamanian, 2000). The genus Asparagus in China is mainly distributed in North China-Northwest China-Southwest China. With the increase of precipitation and temperature in ecological geography, its species distribution shows a relatively decreasing trend (Xu, 2000). Plants of this genus mainly have ornamental, vegetable consumption and medicinal value, such as Asparagus setaceus can be used for ornamental, Asparagus officinalis tender stems for vegetables, Asparagus cochinchinensis tuber has medicinal effect. In view of the inconsistency in the classification and orientation of garden asparagus in academic circles, the classification and research on the existing plants of the genus Asparagus in China has a good role in guiding the interspecific hybrid breeding of garden asparagus.

\subsection{Systematic taxonomy of the genus Asparagus}

The genus Asparagus was first attributed to Liliaceae because it is a plant with unisexual flower and dioecious characteristics. However, the leaves of this genus degenerated into scales, and the branchlets are specialized into leafy branches, which is called pseudo-leaf, and had significant specificity in Liliaceae. It is still a controversial issue for plant taxonomists to leave the genus Asparagus in Liliaceae, or to belong to Ruscuraceae or to be a new family. In the traditional systematic taxonomy (Cronguist, Hutchinson, and Engler), the genus Asparagus was attributed to Liliaceae. While in Takhtajan, it was attributed to Asparagaceae (The Angiosperm Phylogeny Group, 1998). In the Flora of China, garden asparagus belongs to the genus Asparagus of Liliaceae. Liliaceae is a complex group, and its systematic relationship is chaotic (Tang, 1995). 
According to the recent cladistic analyses, the genus Asparagus has been separated from Liliaceae and divided into an independent Asparagaceae (The Angiosperm Phylogeny Group, 1998; Liu et al., 2015; Lu et al., 2018). Subsequently, it was revised to carry out two classifications of Asparagaceae. The narrow classification only included plants of the genus Asparagus, while the broad classification included plants of Asparagaceae, Aphyllanthoideae, Isoporaceae, Restionaceae, Hyacinthaceae, Hesperocallidaceae and Ruscaceae (The Angiosperm Phylogeny Group, 2003). In the taxonomic system of 2009, the horizontal classification range of Asparagaceae in the family was further expanded, including 7 subfamilies, 29 families, 123 genera, and about 2 240 2 390 species of plants (The Angiosperm Phylogeny Group, 2009). In the latest taxonomic system, the genus Asparagus in Asparagaceae is further divided into the Subgenus Asparagus, Myrsiphyllum, Protas-paragus and the recently added subgenus Hemiphylacus in Mexico (The Angiosperm Phylogeny Group, 2016). Therefore, the taxonomic relationship between genera is not clear, and within genera is also controversial. The annotation of the whole sequence map of the genus Asparagus (NCBI accession number: NC_034777.1) was completed by chloroplast genome sequencing, and the phylogenetic analysis was carried out by using 77 coding gene sequences of Asparagus officinalis and related wild species chloroplast genome in this study. The results showed that the Asparagus officinalis had the farthest genetic relationship with Lilium distichum in Liliaceae and the closest genetic relationship with Polygonatum cyrtonema in Asparagaceae. Therefore, through the systematic taxonomic research, it is confirmed that the phylogenetic relationship of this genus is inconsistent with the classical systematic taxonomy, which needs taxonomic revision.

\section{Molecular Phylogeny of the Genus Asparagus}

\subsection{Molecular phylogeny of the genus Asparagus in China}

In the process of studying the classification of Liliaceae, Tang and Liang (1983) thought it was disordered and needed more extensive research on morphological characteristics. Based on this, to solve the problem of systematic taxonomy of the genus Asparagus plants, especially the genetic relationship between genera and species within the genus, $\mathrm{Ni}$ and Zhao (1990) compared the pollen morphology of 14 species of the genus Asparagus from Gansu by light microscope and scanning electron microscope, and then discussed the variation relationship between the species from the aspects of pollen morphological characteristics. It was concluded that the pollen grains of these plants were left and right symmetrical, with single hole, single grain, and round, and had no significant variation with the pollen of other genera of Liliaceae. Zhang and Qin (1992) investigated the resources of the genus Asparagus from Sichuan, carried out morphological classification, and found a total of 14 plant types. Tang (1995) classified the genus Asparagus into Liliaceae according to the convergent character of berries. $\mathrm{Xu}$ et al. (2005) identified 13 species (including 2 cultivated species) and 1 variety of the genus Asparagus L. in Mongolian Plateau. And according to the distributive characteristics of ecological geography of the genus Asparagus, it is inferred that this genus evolved after the separation of Eurasia and North America (Xu et al., 2002). The genus Asparagus L. in Mongolian Plateau can be divided into subgenus Asparagus and Protas-paragus (Xu et al., 2003). Meanwhile, Liu (2018) found three species of the genus Asparagus in northern Tangshan.

Huang et al. (2010) found that four species of the genus Asparagus could be identified by chloroplast trnL-F sequence. Ou et al. (2010; 2011) believed that ITS has some limitations in the study of systematic taxonomy, and it is necessary to combine other means to accurately study the systematic development of the genus Asparagus. Similarly, the results of phylogenetic analysis within the genus Asparagus using trnH-psbA sequence had certain limitation and the classification of some species deserves further study (Ou et al., 2013). Therefore, the systematic taxonomy of genus Asparagus in China has only carried out the molecular phylogeny of morphology and a few gene sequences, which does not clearly show the phylogenetic relationship between the closely related species of this genus, seriously restricting the development and utilization of the genus resources.

\subsection{Molecular phylogeny of the genus Asparagus abroad}

Foreign scholars earlier believed that the taxonomic status of the genus Asparagus was controversial and proposed the attribution of taxonomic status. Kubituki and Rudall (1998) suggested that the genus Asparagus should be 
raised to the status of family, and included subgenus Asparagus, Protas-paragus, and Myrsiphyllum. Kanno and Yokoyama (2011) believed that the genus Asparagus included three subgenera, and that Africa, especially South Africa, is the diversity center of the genus. Lee et al. (1997) first used the RFLP polymorphism of chloroplast DNA (cpDNA) in genus Asparagus to construct the molecular phylogenetic relationship of Asparagus officinalis L., which could distinguish diploid and polyploid species into two branches and inferred that Asparagus officinalis L. was monophyletic. Stajner et al. (2002) divided the 10 tested materials into two groups using RFLP markers, which were related to gender differences and geographical origin, and the results of phylogenetic research were consistent with botanical classification. Fukuda et al. (2005) showed that the emergence of gender phenomenon was monophyletic origin in the genus Asparagus. The study on gender determination sites and genetic variation of gender chromosomes in the genus Asparagus species could explore the evolutionary prototype of gender chromosomes and the law of gender chromosome differentiation. And it is considered that that this genus plants had spread to other parts of the Old World through a large number of species domestication and hybridization. Kuhl et al. (2006) believed that in the order Asparagales, plants of the genus Asparagus with small genomes could be used as a model for genome analysis, but no genome duplication event between European and South African groups was observed. Moreno et al. (2008b) used ITS sequences to identify the genus Asparagus plants, which may be related to the genetic relationship between the two selected experimental materials.

Kim et al. (2012) used 5 cpDNA sequences to carry out the phylogenetic work of the order Asparagales in South Korea. The results showed that the cpDNA sequence could identify the phylogenetic relationship between species. Boonsom et al. (2012) found that PCR-RFLP analysis of $m a t K$ gene was an effective method for authentication of A. racemosus, a closely related species of Asparagus officinalis L. Kubota et al. (2012) constructed a phylogenetic tree using non-coding cpDNA sequences, and pointed out that this genus originated from South Africa, and then evolved into various regions of the Old World. The results showed that the dioecious species were derived from a single evolutionary transition from hermaphroditism. Chen et al. (2013) used 4 cpDNA sequences to study the phylogeny of the order Asparagales. Castro et al. (2013) analyzed the ITS and EST-SSR of the genus Asparagus and its interspecific hybrids, and found that the germplasm resources of this genus can be divided into two categories, one is related to A.acutifolius, the other is related to A.officinalis. Mousavizadeh et al. (2015) divided the 4 species of the genus Asparagus into two categories through the analysis of morphological traits, one included accessions of two species A.officinalis and A.breslerianus, the other included A.persicus and A.verticillatus. Phylogenetic analysis showed that the dioecious species of the genus Asparagus shared a common origin, which was formed after one or two evolutions. At the same time, with the increase of genome size and repeat sequence, its distribution area also expanded from southern Africa to northern and Europe (Norup et al., 2015). Saha et al. (2015) confirmed that the monoecious subgenus Protas-paragus with the monophyletic origin of the dioecious subgenus Asparagus by analyzing the rDNA ITS and cpDNA trnL intron sequences of the genus Asparagus and morphological characteristics of phyllodes. Li et al. $(2014 ; 2016)$ believed that the polymorphism of transposable elements in the genome of Asparagus officinalis is related to the systematic evolution of this genus. Harkess et al. (2016) distinguished dioecious plants from monoecious plants by the sequence polymorphism of transposable elements and speculated that the amplification of transposable elements is related to the size of the genome. Mousavizadeh et al. (2015) suggested that polyploidization played a role in the evolution of the genus Asparagus, and different species had different 5S and 45S rDNA. Akter et al. (2017) and Boubetra et al. (2017) carried out the karyotype analysis of the genus. It was concluded that the chromosome karyotype base number of the genus was 10, including diploid, tetraploid, hexaploid and even octaploid. Altıntaş et al. (2019) analyzed the molecular phylogenetic tree of the genus Asparagus plants and believed that ITS sequence was better than cpDNA trnL intron sequence to explain the genetic relationship between them. Li et al. (2019) believed that the infiltration of chloroplast genome increased the complexity of nuclear genome of Asparagus officinalis L. composition. As this genus has important medicinal chemical components, Doménech-Carbonó et al. (2016) concluded that the analysis of chemical volatile components can effectively distinguish plant types in subgenus Asparagus, Protas-paragus, and Myrsiphyllum. According to the genetic relationship between the genus Asparagus and A. officinalis, A. officinalis has carried out interspecific 
hybridization with A.schoberioides (Ito et al., 2007) and Asparagus kiusianus (Ito et al., 2011). However, previous studies based on morphology, rDNA sequence and single or a few cpDNA genes to construct phylogenetic relationships have not completely solved the systematic taxonomy of the genus Asparagus and its above genera. At the same time, there is no detailed and comprehensive description of the interspecific relationship below genera, especially the taxonomic and genetic relationship between wild genus Asparagus species in China and $A$. officinalis, which needs continuous revision and improvement.

Our team has completed the chloroplast genome sequencing work using the collected wild species (A. dauricus, $A$. densiflorus, A. setaceus), and compared and analyzed the protein coding gene sequences. It is confirmed that the polymorphism of chloroplast genome coding gene sequence can well distinguish the species with complex genetic relationship and difficult classification, and it is concluded that Asparagus dauricus and Asparagus officinalis has the closest genetic relationship. And the early cooperation of the team (Jiangxi Academy of Agricultural Sciences, together with Shenzhen Huada Gene Research Institute, University of Georgia, Institute of Botany, the Chinese Academy of Sciences and other units.) firstly reported a high coverage (93.7\%) of Asparagus officinalis whole-male genome sequence map and annotated 36,763 genes (Harkess et al., 2017), as well as verified at the molecular level that the SOFF-asTDF1 of Asparagus officinalis could control its gender determination, and that single-copy nuclear genes such as gender determination genes could be used to study the genetic relationship of this genus (Harkess et al., 2020). With the release of high-precision genome sequence map for A. officinalis, A. officinalis has been further promoted to become a model plant for gender determination and differentiation research (Harkess et al., 2015; 2016; Tsugama et al., 2017; Zhou et al., 2018). At the same time, a series of important biological scientific issues such as genetic diversity (Mercati et al., 2015), molecular phylogenetic development ( $\mathrm{Li}$ et al., 2020), origin and domestication (Murase et al., 2016) of the genus Asparagus germplasm resources will be more focused on.

Many practical studies have also shown that the phylogeny of organelles is an important means to straighten out the relationship between species (Lei et al., 2019; Ge et al., 2020). Therefore, we proposed that the study of genetic variation at the whole genome level is an effective method to solve the taxonomic status of the genus, and will focus on the sequence variation polymorphism of the organelle genome and nuclear genome, to carry out the genetic variation of cultivated species and wild species in A. officinalis L., and to further sort out the phylogenetic relationship, and then solve the key bottleneck problem of low genetic diversity in A. officinalis L. breeding practice.

\section{Problems and Prospects of Systematic Taxonomy Study on the Genus Asparagus}

\subsection{The systematic taxonomy status of important group of genus Asparagus in China needs to be established} urgently

The plants of the genus Asparagus have important ornamental and horticultural value, economic edible value and medicinal value. The plants widely used and cultivated by human beings in this genus are $A$. officinalis, which is used as valuable vegetable; $A$. cochinchinensis, which is used for Traditional Chinese Medicine; A. racemosus, which is used for Traditional Indian Medicine; and A. setaceus, A. densiflorus, A. retrofractus, which is used for landscaping. Studying the phylogenetic relationships within the genus is of great significance for germplasm conservation, utilization, and genetic breeding. For the study of this genus, it is necessary to continue to expand the construction of the genus Asparagus germplasm resource nursery and clarify the phylogenetic relationship between 31 species of this genus in China and foreign resources based on further introduction of foreign germplasm.

\subsection{Research methods and techniques need to be updated urgently}

At present, most studies on phylogeny of genus Asparagus are based on phylogenetic trees constructed by single gene or several gene fragments. However, in the study of molecular phylogeny, gene sequences, protein sequences and chemicals are all important research objects. In the research methods, in addition to the classical morphological observation and tissue structure anatomy, the combined methods of genomics, proteomics, metabonomics and transcriptomics are all important research methods. 
Therefore, with the maturity of three-generation sequencing technology, molecular phylogenetic genomics will be more widely used. Phylogenetic genomics based on multi-gene association method will deeply solve the inconsistency of phylogenetic trees constructed by different types of source sequences. In addition to genome sequence changes, protein domain is also the basic unit of gene evolution. The phylogenetic tree constructed by protein domain information library such as Pfam will be another important research field. Therefore, the next step will be to solve the problem of systematic taxonomy of the genus based on the comprehensive application of chloroplast, mitochondria, nuclear genome, proteome, chemistry, morphoanatomy.

\subsection{The next research direction of phylogeny of this genus}

Plants in this genus have various traits, including herbs, shrubs and vines, photosynthetic stems (pseudo-leaves), leaves degenerated into scales, black or red berries, all of which are characteristic traits. Therefore, the evolution of characteristic traits in this genus is an important research direction. In addition, a remarkable feature of this genus is the rich variability of its reproductive system, including monoecious, dioecism, hermaphroditic, male monoecious, and even supermale (Kanno and Yokoyama, 2011). Kubota et al. (2012) showed that the genus Asparagus is monophyletic, and its gender diversity and chromosome ploidy are the driving force of its evolution. $\mathrm{Li}$ et al. (2014) proposed that the transposable elements is beneficial to the study of the hermaphroditic origin of $A$. officinalis L. The genome sequence of A. officinalis L. is mainly composed of transposons and its type is Ty1/copia. Phylogenetic analysis showed that the dioecious species of the genus Asparagus was formed after one or two evolutions (Norup et al., 2015). Harkess et al. (2015; 2017; 2020) studied the phylogenetic relationship of plant gender-determining genes, suggesting that genome duplication events set time for the evolution of female inhibitory function and the emergence of gender phenomena in the genus Asparagus species. Moreover, tetraploid and hexaploid phenomena are common in the genus Asparagus. Some species have diploid and tetraploid, and some have tetraploid and hexaploid. A. officinalis L. is a typical plant with diploid and tetraploid phenomena (Mousavizadehb et al., 2011). The study on these genetic phenomena will provide research ideas for solving the phylogenetic relationship among Asparagus plants.

Therefore, the adaptation and domestication mechanisms of genus Asparagus species are significantly correlated with gender polymorphism, chromosome polyploidization and genome size. Based on this, we believe that in the study of systematic evolution of the genus Asparagus, the next step will focus on solving hot issues such as gender polymorphism of Asparagus plants, the origin of tetraploid A. officinalis L., the domestication of wild $A$. officinalis L., and the phylogenetic relationship between cultivated A. officinalis L. and other species of this genus.

\section{Authors' contributions}

Manuscript written and revised by Wentao Sheng; references collected by Tonglin Zhang and Zhangfeng Wang; manuscript proofread by Quan Kuang; manuscript devised and revised by Shaochun Luo. All authors read and approved the final manuscript.

\section{Acknowledgments}

The study was supported by Natural Science Foundation of Jiangxi Province (20171BAB214024;), Science and Technology Project of Department of Education of Jiangxi Province (GJJ202619), and the "11531" Project and Doctoral Foundation Project of Nanchang Normal University (NSBSJJ2015036).

\section{Reference}

Akter S., Begum K.N., Sultana S.S., and Alam S.S., 2017, Karyotype diversity in three Asparagus L. species, Cytologia, 82: 551-557 https://doi.org/10.1508/cytologia.82.551

Altıntaş S., Pakyürek M., Şensoy S., Erez M.E., and İnal B., 2019, Genetic diversity among some Asparagus species using rDNA ITS, cpDNA trnL intron sequence and screening for antioxidant activity, Polish Journal of Environment Studies, 28(4): 1-7 https://doi.org/10.15244/pjoes/89979

Boonsom T., Waranuch N., Ingkaninan K., Denduangboripant J., and Sukrong S.,2012, Molecular analysis of the genus Asparagus based on matK sequences and its application to identify A. racemosus, a medicinally phytoestrogenic species, Fitoterapia, 83: 947-953 
Boubetra K., Nabila A.N., and Rachid R., 2017, Comparative morphological and cytogenetic study of five Asparagus (Asparagaceae) species from Algeria including the endemic A. altissimus Munby, Turkish Journal of Botany, 41: 588-599 https://doi.org/10.3906/bot-1612-63

Castro P., Gil J., Cabrera A., and Moreno R., 2013, Assessment of genetic diversity and phylogenetic relationships in Asparagus species related to Asparagus officinalis, Genet. Resour. Crop Evol., 60: 1275-1288 https://doi.org/10.1007/s10722-012-9918-3

Chen S.C., and Tamanian K.G., 2000, 41. ASPARAGUS Linnaeus, Sp. Pl. 1: 313. 1753. Flora of China, 24: 208-215

Chen S.C., Kim D.K., Chase M.W., and Kim J.H., 2013, Molecular analysis of the genus Asparagus based on $m a t K$ sequences and its application to identify A. racemosus, a medicinally phytoestrogenic species, PLoS One, 8(3): e59472

Doménech-Carbó A., Ibars A.M., Prieto-Mossi J., Estrelles E., Domench-Carbo M.T., Ortiz-Miranda A.S., Martini M., and Lee Y., 2016, Access to phylogeny from voltammetric fingerprints of seeds: the Asparagus case, Electroanalysis, 28: 1-9 https://doi.org/10.1002/elan.201600588

Fukuda T., Ashizawa H., Suzuki R., Nakamura T., Ochiai T., Kanno A., Kameya T., and Yokoyama J., 2005, Molecular phylogeny of the genus Asparagus (Asparagaceae) inferred from plastid petB intron and petD-rpoA intergenic spacer sequences, Plant Species Biology, 20: 121-132 https://doi.org/10.1111/j.1442-1984.2005.00131.x

Ge Q.Y., Cai Y., Wang J.F., and Zhao S.G., 2020, Complete genome analysis of mtDNA in Carp and Crucian, Jiyinzuxue yu Yingyong Shengwuxue (Genomics and Applied Biology), 39(1): 37-43

Harkess A., Huang K., Hulst R.V.D., Tissen B., Caplan J.L., Koppula A., Batish M., Meyers B.C., and Leebens-Mack J., 2020, Sex determination by two Y-linked genes in garden Asparagus, Plant Cell, 2020, 32(6): 1790-1796

https://doi.org/10.1105/tpc.19.00859 PMid:32220850 PMCid:PMC7268802

Harkess A., Mercati F., Abbate L., McKain M., Pires C., Sala T., Sunseri F., Falavigna A., and Leebens-Mack J., 2016a. Retrotransposon proliferation coincident with the evolution of dioecy in Asparagus, Genes Genomes Genetics, 6: 2679-2685 https://doi.org/10.1534/g3.116.030239

Harkess A., Mercati F., Shan H.Y., Sunseri F., Falavigna A., and Leebens-Mack J., 2015, Sex-biased gene expression in dioecious garden asparagus (Asparagus officinalis), New Phytologist, 207(3): 883-892 https://doi.org/10.1111/nph.13389 PMid:25817071

Harkess A., Zhou J.S., Xu C.Y., Bowers J.E., Hulst R.V.D., Ayyampalayam S., Mercati F., Riccardi P., McKain M.R., Kakrana A., Tang H.B., Ray J., Groenendijk J., Arikit S., Sandra M., Mathioni S.M., Nakano M., Shan H.Y., Telgmann-Rauber A., Kanno A., Yue Z., Chen H.X., Li W.Q.,Chen Y.L., Xu X.Y., Zhang Y.P., Luo S.C., Chen H.L., Gao J.M., Mao Z.C., Pires J.C., Luo M.Z., Kudrna D., Wing R.A.,Meyers B.C., Yi K.X., Kong H.Z., Lavrijsen P., Sunseri F., Falavigna A., Ye Y., Leebens-Mack J.H., and Chen G.Y., 2017, The asparagus genome sheds light on the origin and evolution of a young Y chromosome, Nat. Commun., 8(1): 1279 https://doi.org/10.1038/s41467-017-01064-8 PMid:29093472 PMCid:PMC5665984

Huang Y., Wang Y.R., Tang Y., Liu J.M., Li B., and Ou L.J., 2010, TrnL-F Sequence analysis of 4 species of Asparagus, Huaihua Xueyuan Xuebao (Journal of Huaihua University), 29(11): 63-65

Ito T., Konno I., Kubota S., Ochiai T., Sonoda T., Hayashi Y., Fukuda T., Yokoyama J., Nakayama H., Kameya T., and Kanno A., 2011, Production and characterization of interspecific hybrids between Asparagus kiusianus makino and A. officinalis L., Euphytica, 182: 285-294 https://doi.org/10.1007/s10681-011-0508-9

Ito T., Ochiai T., Aizawa H., Shimodate T., Sonoda T., Fukuda T., Yokoyama J., Kameya T., and Kanno A., 2007, Production and analysis of reciprocal hybrids between Asparagus officinalis L. and A. schoberioides Kunth, Genetic Resources and Crop Evolution, 54(5): 1063-1071 https://doi.org/10.1007/s10722-006-9186-1

Kanno A., and Yokoyama J., 2011, Asparagus, wild crop relatives: genomic and breeding resources, Springer-Verlag Press, pp. 23-42 https://doi.org/10.1007/978-3-642-20450-0_3

Kim D.K., Kim J.S., and Kim J.H., 2012, The phylogenetic relationships of Asparagales in Korea based on five plastid DNA regions, Journal of Plant Biology, 55(4): 325-341 https://doi.org/10.1007/s12374-011-0016-4

Kubituki K., and Rudall P.J., 1998, Asparagaceae in the families and genera of vascular plants (ed Kubituki, K.), Springer-Verlag Press, pp.125-129 https://doi.org/10.1007/978-3-662-03533-7_ 15

Kubota S., Konno I., and Kanno A., 2012, Molecular phylogeny of the genus Asparagus (Asparagaceae) explains interspecific crossability between the garden asparagus (A. officinalis) and other Asparagus species, Theor. Appl. Genet., 124: 345-354 
Kuhl J.C., Havey M.J., Martin W.J., Cheung F., Yuan Q.P., Landherr L., Hu Y., Leebens-Mack J., Town C.D., and Sink K.C., 2006, Comparative genomic analyses in Asparagus, Genome, 1060: 1052-1060 https://doi.org/10.1139/g05-073

PMid: 16391674

Li S.F., Wang J., Dong R., Zhu H.W., Lan N.N., Zhang Y.L., Li N., Deng C.L., and Gao W.J., 2020, Chromosome-level genome assembly, annotation and evolutionary analysis of the ornamental plant Asparagus setaceus, Horticulture Research, 7: 48 https://doi.org/10.1038/s41438-020-0271-y PMCid:PMC7109074

Lee Y., Kanno A., and Kameya T., 1997, Phylogenetic relationships in the genus asparagus based on the restriction enzyme analysis of the chloroplast DNA, Breeding Science, 47: 375-378 https://doi.org/10.1270/jsbbs1951.47.375

Lei H., Zhu S.J, Zhao Y., and Duan X.X., 2019, Sequencing and characteristic analysis of the complete chloroplast genome of Trollius chinensis, Jiyinzuxue yu Yingyong Shengwuxue (Genomics and Applied Biology), 38(8): 3595-3604

Li S.F., Gao W.J., Zhao X.P., Dong T.Y., Deng C.L., and Lu L.D., 2014, Analysis of transposable elements in the genome of Asparagus officinalis from high coverage sequence data, PLoS One, 9(5): e97189 https://doi.org/10.1371/journal.pone.0097189 PMid:24810432 PMCid:PMC4014616

Li S.F., Li J.R., Wang J., Dong R., Jia K.L., Zhu H.W., Li N., Yuan J.H., Deng C.L., and Gao W.J., 2019, Cytogenetic and genomic organization analyses of chloroplast DNA invasions in the nuclear genome of Asparagus officinalis L. provides signatures of evolutionary complexity and informativity in sex chromosome evolution, BMC Plant Biology, 19: 361 https://doi.org/10.1186/s12870-019-1975-8 PMid:31419941 PMCid:PMC6698032

Li S.F., Zhang G.J., Li X., Wang L.J., Yuan J.H., Deng C.L., and Gao W.J., 2016, Genome-wide identification and validation of simple sequence repeats (SSRs) from Asparagus officinalis, Molecular and Cellular Probes2016,30(3): 153-160 https://doi.org/10.1016/i.mcp.2016.03.003 PMid:26987412

Li S.F., Wang J., Dong R., Zhu H.W., Lan L.N..Zhang Y.L., Li N., Deng C.L., and Gao W.J., 2020, Chromosome-level genome assembly, annotation and evolutionary analysis of the ornamental plant Asparagus setaceus, Horticulture Research, 7: 48 https://doi.org/10.1038/s41438-020-0271-y PMCid:PMC7109074

Liu B., Ye J.F., Liu S., Wang Y., Yang Y., Lai Y.J., Zeng G., and Lin Q.W., 2015, Families and genera of Chinese angiosperms: a synoptic classification based on APG III, Shengwu Duoyangxing (Biodiversity Science), 23(2): 225-231 https://doi.org/10.17520/biods.2015052

Liu Y.P., 2018, A survey of the genus Asparagus L. in northern Tangshan, Jilin Nongye (Jinlin Agriculture),3: 95

Lu L.M., Mao L.F., Yang T., Ye J.F., Liu B., Li H.L., Sun M., Miller J.T., Mathews S., Hu H.H., Niu Y.T., Peng D.X., Chen Y.H., Smith S.A., Chen M., Xiang K.L., Le C.T., Dang V.C., Lu A.M., Soltis P.S., Soltis D.E., Li J.H., and Chen Z.D., 2018, Evolutionary history of the angiosperm flora of China, Nature, 554(7691): 234-238 https://doi.org/10.1038/nature25485

Mercati F., Riccardi P., Harkess A., Saka T., Abenavoli M.R., Leebens-Mack J., Falavigna A., and Sunseri F., 2015, Single nucleotide polymorphism-based parentage analysis and population structure in garden asparagus, a worldwide genetic stock classification, Molecular Breeding, 35: 59-70 https://doi.org/10.1007/s11032-015-0217-5

Moreno R., Espejo J.A., Cabrera A., and Gil J., 2008b, Origin of tetraploid cultivated asparagus landraces inferred from nuclear ribosomal DNA internal transcribed spacers' polymorphisms, Ann. Appl. Biol., 153: 233-241 https://doi.org/10.1111/j.1744-7348.2008.00254.x

Moreno R., Espejo J.A., Moreno M.T., and Gil J., 2008a, Collection and conservation of 'Morado de Huetor' Spanish tetraploid asparagus landrace, Genet. Resour. Crop Evol., 55(6): 773-777 https://doi.org/10.1007/s10722-008-9358-2

Mousavizadeh S.J., Hassandokht M.R., and Kashi A., 2015, Multivariate analysis of edible Asparagus species in Iran by morphological characters, Euphytica, 206: $445-4571$ https://doi.org/10.1007/s10681-015-1508-y

Mousavizadehb S.J., Hassandokht M.R., Kashi A., Gil J., Cabrera A., and Moreno R., 2011, Physical mapping of 5S and 45S rDNA genes and ploidy levels of Iranian Asparagus species, Scientia Horticulturae, 211: 269-276 https://doi.org/10.1016/j.scienta.2016.09.011 
Murase K., Shigenobu S., Fujii S., Ueda K., Murata T., Sakamoto A., Wada Y., Yamaguchi K., Osakabe Y., Osakabe K., Kanno A., Ozaki Y., and Takayama S., 2016, MYB transcription factor gene involved in sex determination in Asparagus officinalis, Genes Cells, 22: 115-123 https://doi.org/10.1111/gtc. 12453 PMid:27869347

Ni J.M., and Zhao R.N., 1990, SEM and LM observation of the pollen of the genus Asparagus in Gansu, Lanzhou Yixueyuan Xuebao (Journal of Lanzhou Medical College), 16(1): 17-19

Norup M.F., Petersen G., Burrows S., Bouchenak-Khelladi Y., Leebens-Mack J., Pires J.C., Linder H.P., Seberg O., 2015, Evolution of Asparagus L. (Asparagaceae): out-of- South-Africa and multiple origins of sexual dimorphism, Molecular Phylogenetics Evolution, 92: 25-44 https://doi.org/10.1016/i.ympev.2015.06.002 PMid:26079131

Ou L.J., Sun H.J., Wei G., and Wang Z.X., 2013, Comparison of trnH-psbA sequences of some species in Asparagus, Shizhen Guoyi Guoyao (Lishizhen Medicine and Materia Medica Research), 24(11): 2678-2679

Ou L.J., Ye W., Zheng G.P., Jiang X.H., Shen C.W., Xu D., and Yang J.Q., 2010, Comparison of rDNA internal transcribed spacer sequences in Asparagus, Zhongyaocai (Journal of Chinese Medicinal Materials), 33(10): 1542-1549

Ou L.J., Zhang R.W., Tan Z.W., Zhao T.T., and Shen C.W., 2011, Nuclear DNA ITS sequence analysis of Asparagus cochinchinensis from different geographical regions in China, Zhongcaoyao (Chinese Traditional and Herbal Drugs), 42(7): 1402-1406

Saha P.S., Ray S., Sengupta M., and Jha S., 2015, Molecular phylogenetic studies based on rDNA ITS, cpDNA trnL intron sequence and cladode characteristics in nine Protasparagus taxa, Protoplasma, 252: 1121-1134

https://doi.org/10.1007/s00709-014-0746-5

PMid:25534258

Stajner N., Bohanec B., and Javornik B., 2002, Genetic variability of economically important Asparagus species as revealed by genome size analysis and rDNA ITS polymorphisms, Plant Science, 162: 931-937 https://doi.org/10.1016/S0168-9452(02)00039-0

Tang Y.C., 1995, Notes on changes in classification of Liliaceae (S.L.) and perspective in China, Zhiwu Fwnlei Xuebao (Acta Phytotaxonomica Sinica), 33(1): $1-26$

Tang Y.C., and Liang S.Y., 1983, A preliminary survey and comments on future studies of Chinese Liliaceae, Zhiwu Yanjiu (Bulletin of Botanical Research), 3(2): 56-72

The Angiosperm Phylogeny Group, 1998, An ordinal classification for the families of flowering plants, Annals of the Missouri Botanical Garden, 85(4): 531-553 https://doi.org/10.2307/2992015

The Angiosperm Phylogeny Group, 2003, An update of the angiosperm phylogeny group classification for the orders and families of flowering plants: APG II, Botanical Journal of the Linnean Society, 141: 399-436 https://doi.org/10.1046/j.1095-8339.2003.t01-1-00158.x

The Angiosperm phylogeny group, 2009, An update of the angiosperm phylogeny group classification for the orders and families of flowering plants: APG III, Botanical Journal of the Linnean Society, 161: 105-121 https://doi.org/10.1111/j.1095-8339.2009.00996.x

The Angiosperm Phylogeny Group, 2016, An update of the angiosperm phylogeny group classification for the orders and families of flowering plants: APGIV, Botanical Journal of the Linnean Society, 181(1): 1-20 https://doi.org/10.1111/boj.12385

Tsugama D., Matsuyama K., Ide M., Hayashi M., Fujino K., and Masuda K., 2017, A putative MYB35 ortholog is a candidate for the sex-determining genes in Asparagus officinalis, Scientific Reports, 7: 41497 https://doi.org/10.1038/srep41497

Xu J., 2000, Taxonomy, branching and floristic ecology of Asparagus in the Mongolian Plateau, Thesis for M.S., Inner Mongolia University, Supervisor: Zhao Y.Z., pp.4-28

Xu J., Zhao Y.Z., and Liu G.X., 2005, Study on taxonomy of the genus Asparagus L. in Mongolian Plateau, Zhongguo Caodi (Grassland of China), 5: 10-17

Xu J., Zhao Y.Z., and Tan Q.H., 2002, Study on floristic geographical distribution of Asparagus in Mongolian Plateau, NeiMongol Daxue Xuebao (Acta Scientiarum Naturalium Universitatis NeiMongol (Natural Science Edition)), 33(2): 167-176

Xu J., Zhao Y.Z., and Tian G.Q., 2003, Cladistic evolution analysis of Asparagus genus in the Mongolian Plateau, NeiMongol Daxue Xuebao (Acta Scientiarum Naturalium Universitatis NeiMongol (Natural Science Edition)), 34(3): 325-329

Zhang T.Y., and Qin S.Y., 1992, Study on the btanic resources of Asparaguses in Sichuan Province, Resource Development and Protection, 8(4): 268-269

Zhou J.S., Luo S.C., Zhu Y.L., and Chen G.Y., 2018, Genome sequencing of Asparagus officinalis L.: the beginning of dioecious garden asparagus molecular breeding, Zhongguo Kexue: Shengming Kexue (Scientia Sinica Vitae), 48(10): 1128-1132 